\title{
Unilateral occipital nerve stimulation for bilateral occipital neuralgia: a case report and literature review
}

This article was published in the following Dove Press journal: Journal of Pain Research

20 January 2017

Number of times this article has been viewed

\section{Aijun Liu \\ Yongcheng Jiao \\ Huijun Ji \\ Zhiwen Zhang}

Department of Neurosurgery, First Affiliated Hospital of PLA General Hospital, Beijing, People's Republic of China
Correspondence: Aijun Liu

Department of Neurosurgery, First Affiliated Hospital of PLA General Hospital, 5I Fucheng Road, Haidian, Beijing 100048, People's Republic of China

Tel +86 I35 207| 9338

Email liuaj719@yahoo.com
Objectives: The aim of this study is to present a case of successful relief of bilateral occipital neuralgia (ON) using unilateral occipital nerve stimulation (ONS) and to discuss the possible underlying mechanisms.

Materials and methods: We present the case of a 59-year-old female patient with severe bilateral ON treated with unilateral ONS. We systematically reviewed previous studies of ONS for ON, discussing the possible mechanisms of ONS in the relief of ON.

Results: The patient reported complete pain relief after consistent unilateral ONS during the follow-up period. The underlying mechanisms may be linked to the relationship between pain and several brain regions, including the pons, midbrain, and periaqueductal gray.

Conclusion: ONS is an effective and safe option for treating ON. Future studies will be required to clarify the mechanisms by which unilateral occipital stimulation provided relief for bilateral neuralgia in this case.

Keywords: occipital neuralgia, neuromodulation, peripheral nerve stimulation

\section{Introduction}

Occipital neuralgia $(\mathrm{ON})$ is the third most common headache syndrome following migraine and tension-type headaches. $\mathrm{ON}$ is characterized by severe sharp, shooting, or electric shock pain at the distribution of the occipital nerve. Any stretching or entrapment of the occipital nerve from the second cervical vertebra (C2) to the outlet of the nerve out of the occipital muscle can evoke chronic pain. Several studies with small samples have reported that at least one-third of ON patients exhibit bilateral dysfunction. ${ }^{1,2}$ Occipital nerve stimulation (ONS) has been used to relieve severe pain caused by $\mathrm{ON}$ when conservative medical treatments and block procedures are ineffective. ${ }^{3}$ ONS is a type of neuromodulation, using a spinal cord stimulation device to stimulate the corresponding occipital nerve to treat various types of neuralgia. ONS is minimally invasive, adjustable, and reversible. Here, we present a case in which a patient with refractory bilateral ON was successfully treated with unilateral ONS. In addition, we review previous studies of ONS for treating ON. Finally, we discuss the possible mechanisms by which unilateral ONS relieves bilateral ON.

\section{Case study}

A 59-year-old female presented with severe shooting pain at the distribution of the right occipital nerve 6 months ago. A diagnosis of right $\mathrm{ON}$ was established. The patient's visual analogue score (VAS) was 8-9. The patient had a history of right tympanitis 
and incomplete right hearing loss. The patient was initially medicated with acetaminophen and carbamazepine for 2 months. The pain could not be relieved, and the medicines were changed gradually to baclofen $20 \mathrm{mg}$ three times daily, lamotrigine $100 \mathrm{mg}$ two times daily and pregabalin $150 \mathrm{mg}$ two times daily. This medical treatment had been administered for 1 month, and the patient was still suffering from severe pain without any relief. Moreover, the pain spread from the left side, gradually becoming bilateral ON with VAS 9-10. Percocet $330 \mathrm{mg}$ was then administered every 8 hours, combined with baclofen, lamotrigine, and pregabalin, as described earlier. The patient's VAS was still 8-9. Bilateral occipital block procedures were able to relieve the pain to VAS 2, but relief lasted not $>24$ hours. The long-term pain negatively affected the patient's daily functioning and her body weight decreased by $20 \mathrm{~kg}$ over 6 months. The patient was referred to the Department of Neurosurgery, First Affiliated Hospital of PLA General Hospital, and ONS therapy was recommended. The patient provided written informed consent to have this case and any companying images published. First, a trial implantation was performed. An 8-contact electrode (Medtronic 3778) was inserted percutaneously from the right side to the left, perpendicular to the bilateral occipital nerve course at C1 (Figure 1). An external impulse generator (IPG) was connected to the electrode. The trial stimulation only successfully produced paresthesia covering the left occipital area and did not result in any sensation in the right occipital area under the 1.0-4.0 $\mathrm{V}$ amplitude range. When the amplitude was increased above $5.0 \mathrm{~V}$, only local scalp pain was reported by the patient. An incorrect placement of the lead covering the right occipital nerve was suspected. However, unilateral stimulation still produced bilateral pain relief, to VAS 2-4, and a lead adjustment procedure was refused by the patient. After 7 days of trial stimulation, a permanent IPG (Medtronic PrimeAdvanced) was implanted subcutaneously in the upper

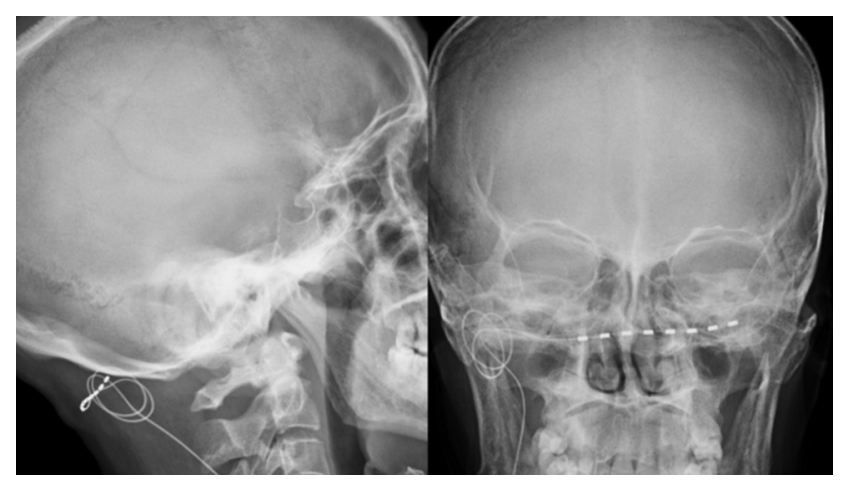

Figure I Lateral and anteroposterior X-ray images of the occipital electrode lead placement. right chest area. When the IPG was switched on, the patient experienced a tickling-like sensation, which substantially relieved the pain. Only the contacts of the electrode covering the left occipital area were used with a pulse width of $120 \mathrm{~ms}$, a frequency of $60 \mathrm{~Hz}$, and an amplitude of 3.0 V. At 3-year follow-up, the patient reported long-lasting pain relief with VAS 0 and no side effects.

\section{Discussion}

The precise mechanisms underlying $\mathrm{ON}$ are currently unclear, but various studies have suggested that whiplash injury, compression of the $\mathrm{C} 2$ nerve, and compression of the upper cervical roots due to arthritic changes in the spine are the leading possible causes. ${ }^{2,4}$ Moreover, everyday activities that compress the occipital nerve have been reported to cause $\mathrm{ON} .{ }^{2}$ Long-term compression of the $\mathrm{C} 2$ nerve has been reported to produce a series of reactions at the dorsal root ganglion and spinal cord, including inflammation, microglia proliferation, neurotransmitter changes, cytokine responses, and ionic channel changes, which eventually induce chronic pain. ${ }^{5,6}$ When pharmacotherapeutic methods for ON patients are unable to relieve pain, surgical interventions are considered an appropriate option. Surgical methods include neurectomy, ${ }^{7} \mathrm{C} 2-\mathrm{C} 3$ decompression, ${ }^{8}$ partial posterior rhizotomy, ${ }^{9}$ radiofrequency ablation, ${ }^{10}$ and peripheral nerve stimulation (PNS). ${ }^{1}$ Among these methods, PNS has the advantages of minimal invasion, adjustability, reversibility, and a low likelihood of complications.

In a literature search of PubMed using the keywords "occipital neuralgia", we obtained a total of 359 articles from January 1960 to August 2014. A supplemental search was performed manually based on the references of several review articles. ${ }^{11,12}$ Upon review by the authors, 45 articles relating to PNS or neuromodulation were identified. The reviewers' assessment yielded 19 review articles, 10 case reports, 10 retrospective case series, 5 technical reports, and 1 prospective case series. Excluding 19 review articles and 12 articles regarding PNS for trigeminal neuralgia, migraine, and other chronic headaches, the remaining 14 articles involved 77 patients suffering from $\mathrm{ON}$ or cervical originating headache treated with PNS (Table 1). ${ }^{1,3,13-24}$

Among the 78 patients in these 14 studies, most of those receiving permanent implants experienced pain relief of at least $50 \%$. Only one patient was reported to suffer from infection. Lead migration and infection were the two leading causes of ONS-related complications, ${ }^{11}$ and no other severe complications were reported. Due to the high efficacy and low risk of PNS, it may be appropriate for use 
Table I Summary of studies of patients with occipital neuralgia and cervicogenic headache treated with occipital nerve stimulation

\begin{tabular}{|c|c|c|c|c|c|c|c|c|c|}
\hline Study name & $\begin{array}{l}\text { Publish } \\
\text { year }\end{array}$ & $\begin{array}{l}\text { Study } \\
\text { design }\end{array}$ & Diagnosis & $\begin{array}{l}\text { Patient } \\
\text { number }\end{array}$ & $\begin{array}{l}\text { Permanent } \\
\text { implant }\end{array}$ & $\begin{array}{l}\text { Lead } \\
\text { type }\end{array}$ & Follow-up & Pain relief & Complications \\
\hline Chivukula et al $\left.\right|^{13}$ & 2014 & $\mathrm{R}$ & ON & 7 & 7 & $N / A$ & $\mathrm{~N} / \mathrm{A}$ & $\mathrm{N} / \mathrm{A}$ & $N / A$ \\
\hline Chaiban et al ${ }^{14}$ & 2014 & C & ON & I & 1 & Cy & Iy & $100 \%$ & None \\
\hline Palmisani et $\mathrm{al}^{3}$ & 2013 & $\mathrm{R}$ & $\mathrm{ON}$ and $\mathrm{CH}$ & 4 & 3 & Cy & $\begin{array}{l}28 \mathrm{~m}, 31 \mathrm{~m} \\
\text { and } 28 \mathrm{~m}\end{array}$ & $100 \%, 70 \%$, and $50 \%$ & None \\
\hline Eldrige et $\mathrm{al}^{15}$ & 2010 & C & ON & I & 1 & Cy & $5 \mathrm{~m}$ & $\mathrm{~N} / \mathrm{A}$ & None \\
\hline Skaribas et $\mathrm{al}^{16}$ & 2010 & $\mathrm{~T}$ & $\mathrm{ON}$ and $\mathrm{CDH}$ & 6 & 6 & Cy & $N / A$ & $\mathrm{~N} / \mathrm{A}$ & $\mathrm{N} / \mathrm{A}$ \\
\hline Magown et al ${ }^{17}$ & 2009 & $\mathrm{~T}$ & ON & 7 & 7 & $\mathrm{~Pa}$ & $2-30 m$ & $\begin{array}{l}100 \% \text { except } 75 \% \text { in } \\
\text { one case }\end{array}$ & none \\
\hline Ghaemi et al ${ }^{18}$ & 2008 & C & ON & 1 & 1 & $\mathrm{~Pa}$ & $12 \mathrm{~m}$ & $90 \%$ & None \\
\hline Johnstone et al ${ }^{19}$ & 2006 & $\mathrm{R}$ & ON & 8 & 7 & $\mathrm{~Pa}$ & Avg $25 \mathrm{~m}$ & $\begin{array}{l}5 \text { had more than } \\
50 \% \text { pain relief }\end{array}$ & None \\
\hline Slavin et al' & 2006 & $\mathrm{R}$ & ON & 14 & 10 & Cy & Avg $22 \mathrm{~m}$ & $\begin{array}{l}8 \text { had satisfying } \\
\text { pain relief }\end{array}$ & One infection \\
\hline Kapural et a ${ }^{20}$ & 2005 & C & ON & 6 & 6 & $\mathrm{~Pa}$ & Avg $3 \mathrm{~m}$ & $\begin{array}{l}\text { Avg VAS from } 8.66 \\
\text { to } 2.5\end{array}$ & None \\
\hline $\begin{array}{l}\text { Rodrigo-Royo } \\
\text { et a }\left.\right|^{21}\end{array}$ & 2005 & C & $\mathrm{CH}$ & 4 & 4 & Cy & $\begin{array}{l}16 \mathrm{~m}, 9 \mathrm{~m}, \\
6 \mathrm{~m} \text { and } 4 \mathrm{~m}\end{array}$ & $\begin{array}{l}100 \%, 100 \%, 90 \% \text {, } \\
\text { and } 100 \%\end{array}$ & None \\
\hline Oh et $\mathrm{al}^{22}$ & 2004 & $\mathrm{P}, \mathrm{T}$ & ON & 10 & 10 & $\mathrm{~Pa}$ & Avg $6 \mathrm{~m}$ & $\begin{array}{l}\text { Self-reported } \\
>50 \% \text { pain relief in } \\
9 \text { patients }\end{array}$ & None \\
\hline Hammer et $\mathrm{al}^{23}$ & 2001 & C & ON & I & 1 & Cy & Avg $9 \mathrm{~m}$ & $80-90 \%$ & None \\
\hline Weiner et $\mathrm{al}^{24}$ & 1999 & $\mathrm{R}$ & ON & 13 & 13 & Cy & $1.5-5.5$ y & $\begin{array}{l}\text { Two-thirds of the } \\
\text { patients had }>75 \% \\
\text { pain relief and } \\
\text { one-third had }>50 \% \\
\text { pain relief }\end{array}$ & None \\
\hline
\end{tabular}

Abbreviations: $\mathrm{R}$, retrospective study; $\mathrm{C}$, case report; $\mathrm{T}$, technical report; $\mathrm{P}$, prospective study; ON, occipital neuralgia; $\mathrm{CH}$, cervicogenic headache; $\mathrm{CDH}$, chronic daily headache; N/A, not available; Cy, cylinder lead; Pa, paddle lead; VAS, visual analogue score; $m$, months; $y$, years; Avg, average.

in patients with poor health. Chaiban et $\mathrm{a}{ }^{14}$ reported the successful treatment of an 86-year-old ON patient with a pacemaker.

The precise mechanism of action of ONS for treating $\mathrm{ON}$ is still under investigation. Bartsch and Goadsby ${ }^{25}$ demonstrated that neurons in the $\mathrm{C} 2$ spinal dorsal horn receive input from the ipsilateral and contralateral occipital nerves. In addition to direct connections between the occipital nerve and the upper cervical spinal cord, a review of brain imaging and ONS research by Bari and Pouratian ${ }^{26}$ reported that the function of many painrelated brain regions can be affected when occipital nerves are stimulated. One study using 3-Tesla magnetic resonance imaging reported activation in the hypothalamus, thalamus, orbitofrontal cortex, prefrontal cortex, periaqueductal gray, inferior parietal lobule, and cerebellum during ONS in a single healthy volunteer. ${ }^{27}$ In addition, deactivation was observed in primary cortices, including primary motor area, visual area, auditory area, and somatosensory area, the amygdala, paracentral lobule, hippocampus, secondary somatosensory cortex, and supplementary motor area, in the same subject. ${ }^{27}$ One positron emission tomography study reported changes in regional cerebral blood flow in the pons, anterior cingulate cortex, cuneus, and left pulvinar after bilateral ONS. ${ }^{28}$ Another study using 18-fluorodeoxyglucose-positron emission tomography in a group of chronic cluster headache patients reported decreased metabolism in the anterior cingulate cortex, midcingulate, left visual cortex, left pulvinar, cerebellum, midbrain, and left lower pons, as well as increased metabolism in the bilateral sensorimotor cortices, when long-term ONS was applied. ${ }^{29}$ These studies indicate that ONS may have widespread effects on the central nervous system, resulting in pain relief. Continuous stimulation of the occipital nerves may produce diverse functional and metabolic changes in many brain regions. In addition, changes in the pons, midbrain, and periaqueductal gray may be involved in bilateral pain relief after unilateral ONS.

\section{Conclusion}

ONS is an effective treatment for ON, with very low risk and a high success rate. ONS may be applicable for other types of headache, including migraine, cluster headaches, and trigeminal neuralgia. This study described a case of unilateral ONS providing effect relief of bilateral $\mathrm{ON}$, indicating that ONS may have widespread effects in the brain and upper spinal cord. 


\section{Disclosure}

The authors report no conflicts of interest in this work.

\section{References}

1. Slavin KV, Nersesyan H, Wess C. Peripheral neurostimulation for treatment of intractable occipital neuralgia. Neurosurgery. 2006;58(1):112-119.

2. Sahai-Srivastava S, Zheng L. Occipital neuralgia with and without migraine: difference in pain characteristics and risk factors. Headache. 2011;51(1):124-128.

3. Palmisani S, Al-Kaisy A, Arcioni R, et al. A six year retrospective review of occipital nerve stimulation practice - controversies and challenges of an emerging technique for treating refractory headache syndromes. $J$ Headache Pain. 2013;14:67.

4. Ehni G, Benner B. Occipital neuralgia and the $\mathrm{C} 1-2$ arthrosis syndrome. J Neurosurg. 1984;61(5):961-965.

5. Zhuo M, Wu G, Wu LJ. Neuronal and microglial mechanisms of neuropathic pain. Mol Brain. 2011;4:31.

6. Zimmermann M. Pathobiology of neuropathic pain. Eur J Pharmacol. 2001;429(1-3):23-37.

7. Murphy J. Occipital neurectomy in the treatment of headache. Results in 30 cases. Md State Med J. 1969;18(6):62-66.

8. Poletti CE. Proposed operation for occipital neuralgia: C-2 and C-3 root decompression. Case report. Neurosurgery. 1983;12(2):221-224.

9. Dubuisson D. Treatment of occipital neuralgia by partial posterior rhizotomy at C1-3. J Neurosurg. 1995;82:581-586.

10. Vu T, Chhatre A. Cooled radiofrequency ablation for bilateral greater occipital neuralgia. Case Rep Neurol Med. 2014;2014:257373.

11. Jasper J, Hayek AS. Implanted occipital nerve stimulators. Pain Physician. 2008;11:187-200

12. Hong J, Ball PA, Fanciullo GJ. Neurostimulation for neck pain and headache. Headache. 2014;54(3):430-444.

13. Chivukula S, Tempel ZJ, Weiner G, et al. Cervical and cervicomedullary spinal cord stimulation for chronic pain: efficacy and outcomes. Neurosurgery. 2014;61(1):214-215.

14. Chaiban G, Tolba R, Eissa H, et al. Successful treatment of occipital neuralgia with implantable peripheral nerve stimulation in a pacemakerdependent patient. Ochsner J. 2014;14(1):119-122.

15. Eldrige JS, Obray JB, Pingree MJ, Hoelzer BC. Occipital neuromodulation: ultrasound guidance for peripheral nerve stimulator implantation. Pain Pract. 2010;10(6):580-585.
16. Skaribas I, Alo K. Ultrasound imaging and occipital nerve stimulation. Neuromodulation. 2010;13(2):126-130.

17. Magown P, Garcia R, Beauprie I, Mendez IM. Occipital nerve stimulation for intractable occipital neuralgia: an open surgical technique. Clin Neurosurg. 2009;56:119-124.

18. Ghaemi K, Capelle HH, Kinfe TM, Krauss JK. Occipital nerve stimulation for refractory occipital pain after occipitocervical fusion: expanding indications. Stereotact Funct Neurosurg. 2008;86(6):391-393.

19. Johnstone CSH, Sundaraj R. Occipital nerve stimulation for the treatment of occipital neuralgia - eight case studies. Neuromodulation. 2006; 9(1):41-47.

20. Kapural L, Mekhail N, Hayek SM, Stanton-Hicks M, Malak O. Occipital nerve electrical stimulation via the midline approach and subcutaneous surgical leads for treatment of severe occipital neuralgia: a pilot study. Anesth Analg. 2005;101(1):171-174. [table of contents].

21. Rodrigo-Royo MD, Azcona JM, Quero J, Lorente MC, Acín P, Azcona J. Peripheral neurostimulation in the management of cervicogenic headache: four case reports. Neuromodulation. 2005;8(4):241-248.

22. Oh MY, Ortega J, Bellotte JB, Whiting DM, Aló K. Peripheral nerve stimulation for the treatment of occipital neuralgia and transformed migraine using a C1-2-3 subcutaneous paddle style electrode: a technical report. Neuromodulation. 2004;7(2):103-112.

23. Hammer M, Doleys DM. Perineuromal stimulation in the treatment of occipital neuralgia: a case study. Neuromodulation. 2001;4(2): $47-51$.

24. Weiner RL, Reed KL. Peripheral neurostimulation for control of intractable occipital neuralgia. Neuromodulation. 1999;2(3):217-221.

25. Bartsch T, Goadsby PJ. Stimulation of the greater occipital nerve induces increased central excitability of dural afferent input. Brain. 2002;125(pt 7): 1496-1509.

26. Bari AA, Pouratian N. Brain imaging correlates of peripheral nerve stimulation. Surg Neurol Int. 2012;3(suppl 4):S260-S268.

27. Kovacs S, Peeters R, De Ridder D, Plazier M, Menovsky T, Sunaert S. Central effects of occipital nerve electrical stimulation studied by functional magnetic resonance imaging. Neuromodulation. 2011;14(1):46-55. [discussion 56-57].

28. Matharu MS, Bartsch T, Ward N, Frackowiak RS, Weiner R, Goadsby PJ. Central neuromodulation in chronic migraine patients with suboccipital stimulators: a PET study. Brain. 2004;127(pt 1):220-230.

29. Magis D, Bruno MA, Fumal A, et al. Central modulation in cluster headache patients treated with occipital nerve stimulation: an FDG-PET study. BMC Neurol. 2011;11:25.
Journal of Pain Research

\section{Publish your work in this journal}

The Journal of Pain Research is an international, peer reviewed, open access, online journal that welcomes laboratory and clinical findings in the fields of pain research and the prevention and management of pain. Original research, reviews, symposium reports, hypothesis formation and commentaries are all considered for publication.

\section{Dovepress}

The manuscript management system is completely online and includes a very quick and fair peer-review system, which is all easy to use. Visit http://www.dovepress.com/testimonials.php to read real quotes from published authors. 